\title{
Dr Williamson and the master speed
}

Location, location, location.

\section{Michael Livingston}

No speed of wind or water rushing by But you have speed far greater. You can

Back up a stream of radiance to the sky, And back through history up the stream

of time.

Robert Frost, The Master Speed (1934)

For immediate release: INVESTIGATION INTO WILLIAMSON DISAPPEARANCECONCLUDES

Princeton, N.J. - April 20, 2012 - Princeton Borough Police Chief Julian Bragg today announced that the investigation into the disappearance of Albert Williamson was closed, after nearly three weeks of intense and often secretive casework. Dr Williamson, a prominent professor of physics in the School of Natural Sciences at the world-renowned Institute for Advanced Study, who disappeared from his basement laboratory at approximately 2:30 in the afternoon of 1 April, has now been officially pronounced dead, a formal conclusion that many in the community had long accepted as inevitable.

"We can move on now, I suppose," said Williamson's colleague, Dr Aleksandar Restovic. “At last we can put Albert to rest - metaphorically, I mean, as recovery of the body obviously isn't feasible."

In a presentation complete with several charts and graphs, accompanied by an investigation team that included Restovic, two other members of Williamson's department at the institute, and Dr Beverly Leitner, the state's chief psychologist, Police Chief Bragg made clear that the root cause of the professor's death was the very thing that had propelled him on his meteoric rise through the physics profession: his single-mindedness.

${ }^{\star}$ The all-absorbing intensity with which Dr Williamson approached his work, ${ }^{\text {, Leit- }}$ ner went on to explain, "contributed not only to his extreme egocentricity, but also to his inability to look beyond the immediate problem at hand. For much of his career, these natural blinders to the surrounding issues of the world were a benefit, allowing him to break new ground in areas long since abandoned by the majority of mainstream scientists. Sadly, it also led to his death."

The investigators revealed that the project that had been consuming so much of the physicist's life in the months before his death, and which he had held in such an unusual amount of secrecy that numerous strange and often fanciful rumours about it had begun to arise even before he vanished, was time-travel. The professor had quietly built, within his laboratory, a machine that could produce what Restovic termed a 'temporal manipulating field'.

${ }^{\alpha}$ Through uncompromising determina-

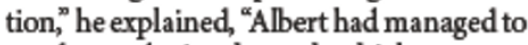
produce a device through which a person could journey to the same spot at a previous moment in time."

Investigators were able to determine that Williamson had made the sudden, and ultimately unfortunate, decision to test the machine himself on April 1, shortly after arguing with his colleagues that morning.

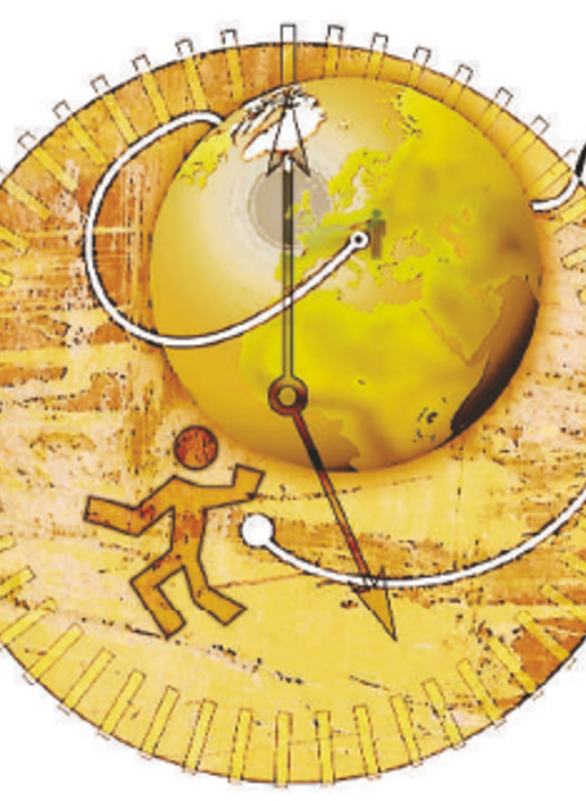

"When we got into work, Al kept bragging about having just completed a time machine," said Dr H. T. Zhang, another of Williamson's colleagues at the institute. ${ }^{\alpha}$ We figured it was his attempt at an April fools' prank, buthe was insistent it was true and so we all argued about it. Things got pretty intense when Sanjay [Patel] said $\mathrm{Al}$ was 'not even wrong." Leitner believes that it was Williamson's intention to prove his colleagues wrong by using his device in order to join them, and himself, for lunch once more.

"At some level he recognized an inability to socialize with others," she said. "He figured the only person capable of communicating well with himself would be another
Albert Williamson. And although his relentless drive to accomplish this rather egocentric goal helped him to succeed in his seemingly quixotic efforts at timetravel, his hopes were doomed to fail."

The failure of Williamson's experiment, as the presentation made clear, was in his thinking so much about time and not enough about space.

${ }^{\alpha}$ We remain fully convinced that Williamson's machine worked: the professor travelled back in time two-and-a-half hours, just as hed planned," Bragg stated. "Yet in his insistence to solve the timetravel problem - a lack of clear thinking compounded by his emotional reaction to arguing with his peers - it simply never occurred to him that he ought to think about the undeniable relationships of time with space."

The Universe is not the static thing that most people assume it to be, the scientists explained. The speed of Earth's rotation at Princeton's latitude, for instance, is approximately 380 metres per second. Meanwhile, Earth is orbiting the Sun at 30 kilometres per second; the Sun is travelling through the Milky Way at 250 kilometres per second; and even the Galaxy itself is moving through space at approximately 300 kilometres per second. Thus, when Dr Williamson passed through his time machine, intending to leap backwards in his laboratory two-and-a-halfhours, he successfully made it to the intended time, but not the intended place: Earth, much less his lab, had not yet arrived at his final destination.

"No doubt Albert felt much elation in the instant before his body was flashfrozen in the void of space, Restovic said.

In answer to a question regarding the two-and-a-half-hour delay between the decision to use the machine and the professor's disappearance into it, Bragg stated that the investigators concluded that Williamson wanted to be sure he would have an appetite for his second lunch. ${ }^{\alpha} \mathrm{He}$ probably thought it would be rude to talk to himself while eating if he wasn't eating himself."

Michael Livingston has published widely in and out of academia, and he currently serves as an assistant profess or of English at The Citadel in Charleston, South Carolina. $H$ is websitecan be found at http://michael. d.livingston googlepages.com. 